\title{
A study to evaluate behavior of society with Covid-19 Frontline health workers
}

\author{
Mayuri Golhar', Tarun Yadav², Harsimran Singh Walia ${ }^{3}$, Sanjay Johar ${ }^{4}$ \\ ${ }^{1,2}$ Assistant Professor, ${ }^{4}$ Professor, Department of Anaesthesiology \& Critical Care, Pt BDS PGIMS, Rohtak, Haryana, \\ India, ${ }^{3}$ Assistant Professor, Department of Anaesthesiology \& Critical Care, Tata Memorial Centre Mullanpur and \\ Sangrur, Punjab, India
}

Background: Health care workers caring for Covid-19 patients go through mental stress, physical exertion, stigma from society and the fear of losing patients' and colleagues. Aims and Objective: To evaluate frontline health care workers perspective about the society's behavior towards them. Materials and Methods: This questionnaire-based study included a total of 648 participants and included 20 questions about demography, Covid duty, health related issues and behavioral aspect of society during Covid duty. Behavioral related responses were scaled on the basis of response score. Results: Suggested that the overall population behavior was satisfactory but behavioral biases were existent. Major health issue of concern that surfaced during duties was stress. Conclusion: Behavioral prejudices are existent due to the stigma attached to this pandemic and hence needs to be addressed with great concern. Health related issues should be dealt promptly and psychological counseling should be made mandatory.

Key words: Stigma; Frontline health care workers; Covid-19; Behavioral bias
http://nepjol.info/index.php/AJMS DOI: 10.3126/ajms.v12i1.30947

E-ISSN: 2091-0576

P-ISSN: 2467-9100

Copyright (c) 2021 Asian Journal of Medical Sciences

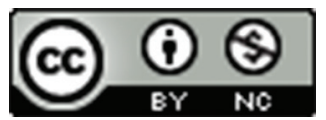

This work is licensed under a Creative Commons Attribution-NonCommercial 4.0 International License.

\section{INTRODUCTION}

At the end of 2019, Novel Coronavirus (COVID-19) emerged in Wuhan, Hubei Province, China. ${ }^{1}$ Reports showed that the COVID-19 infection had caused clusters of symptoms similar to severe acute respiratory syndrome (SARS) Coronavirus. ${ }^{2}$ The virus has raised world concern because of its high transmission capability as well as high morbidity and mortality. Ever since the onset of outbreak of the disease it has spread to almost every part of the world and has already claimed over eight lakhs deaths till august $2020 .{ }^{3}$ But it is not only the disease which is dangerous but the social stigma associated with it. There are worldwide incidents reported where the frontline health care workers faced discrimination and prejudicial treatment by the society while working for coronavirus patients. ${ }^{47}$ So we conducted this questionnaire-based survey to understand the frontline health care workers perspective about the society's behavior towards them.

\section{MATERIALS AND METHODS}

This cross-sectional questionnaire-based study was conducted from April 2020 to July 2020 among doctors, nurses, technicians and other non-technical staff working in frontline for managing COVID 19 patients and participated voluntarily in this survey. All the participants' anonymity and confidentiality were maintained and consent to participate in the study was also obtained. A total of 648 participants were included in the study. Forty-eight participants were later excluded from the study due to incomplete information. Data was collected from an online survey portal Google Form and link to which was shared on social networking platforms. 
Descriptive statistical methods were used to summarize data on demographic characteristics, particulars about COVID-19 duty and different behavioral perceptions of society towards COVID-19 front liners.

Questioner had 20 questions, 3 about demography, 4 Covid duty related, 10 behavioral aspect of society and 3 question about health-related issues during Covid duty. All behavioral related responses were scaled on the basis of responses score on a scale of 1 to 5 , average mean score was calculated and scored as described below. Decimals were rounded to the nearest whole number.

Behavior response score:

\begin{tabular}{ll}
\hline 1 & Awful \\
2 & Bad \\
3 & Good/Satisfactory \\
4 & Very Good \\
5 & Extraordinary \\
\hline
\end{tabular}

Data were summarized as frequencies (n) and percentages (\%) for categorical variables. All data analyses were performed using Statistical Package for the Social Sciences (SPSS) software, version 22. A value of $\mathrm{P}<0.05$ was considered statistically significant.

\section{RESULTS}

Age distribution among health care Covid-19 frontliners

Among the participants, most of the heath care workers were aged between $20-30$ years $50.3 \%(n=302)$ while 32.5 $\%$ were of the age group 30-40 ( $n=195), 13.3 \%$ were aged between 40-50 years $(n=80)$ while $3.8 \%$ were over the age of 50 years $(n=23)$ which showed that we had $82.8 \%$ Covid 19 frontiers who were young and below the age of $40(\mathrm{n}=497) \mathrm{p}$ value $<0.05$ ( Figure 1$)$.

\section{Sex distribution among health care Covid-19 frontliners}

There was a statistically significant difference among the sex distribution. $54.16 \%(n=325)$ of Covid19 frontiers were males and $45.83 \%(n=275)$ were females $\mathrm{p}$ value $>0.05$ (Figure 2).

\section{Categorical distribution of health care Covid-19 frontliners}

Among the different participants $62 \%(\mathrm{n}=372)$ were doctors, $21.5 \%(n=129)$ were Nurses, $1.54 \%$ Lab technicians $(n=10), 4.33 \%$ Sweepers $(n=26), 4.33 \%$ Bearers $(n=26)$ and $6.16 \%(n=37)$ were other health care workers (Figure 3$)$.

\section{Duration of duty among health care Covid-19 frontiers} On calculating the total number of duty days $72 \%(\mathrm{n}=432)$ frontiers were performing Covid 19 duties of less than 7

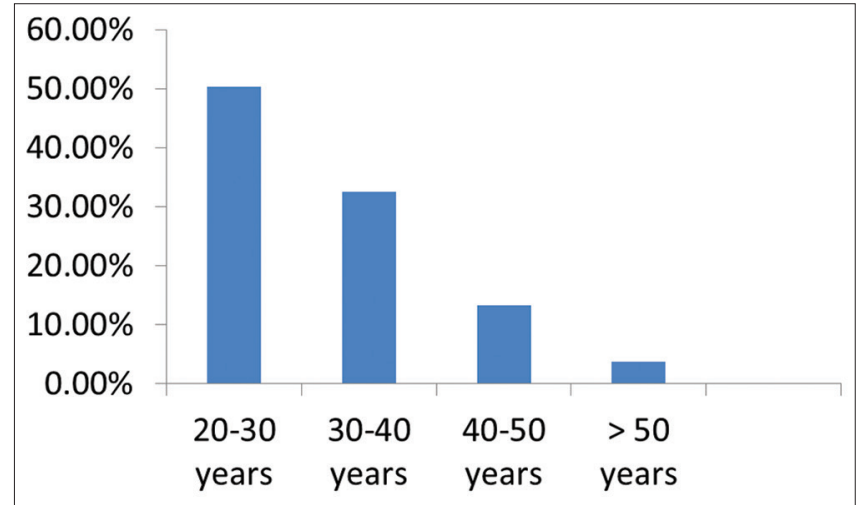

Figure 1: Age Distribution among health care Covid-19 frontliners

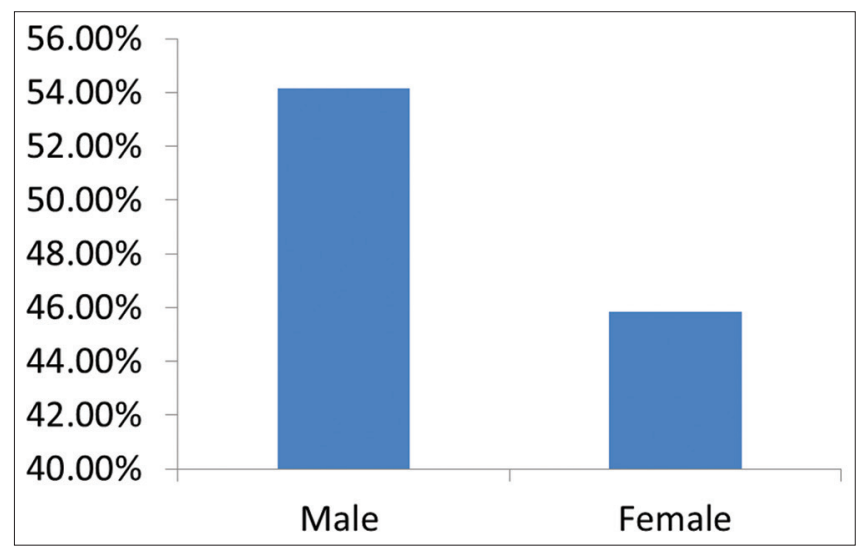

Figure 2: Sex Distribution among health care Covid-19 frontliners

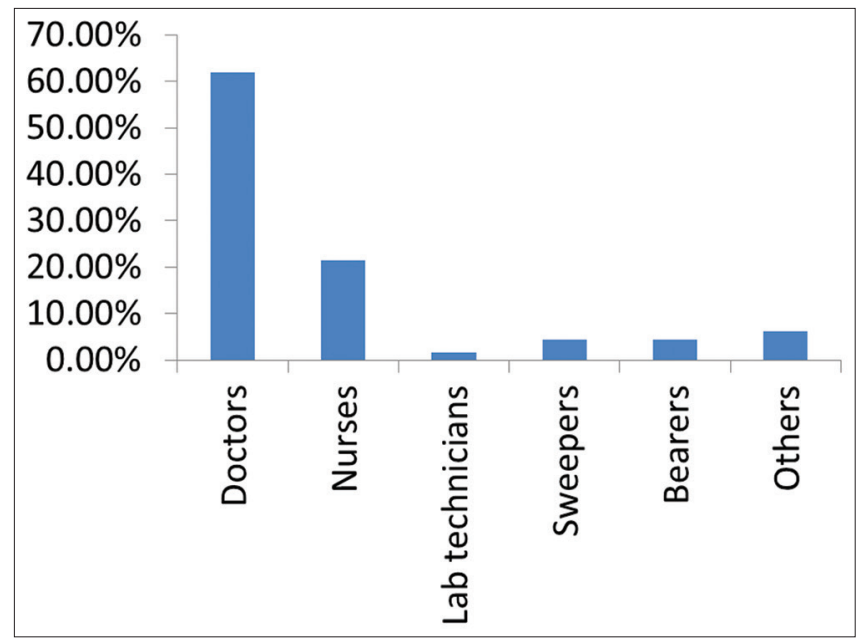

Figure 3: Categorical distribution of health care Covid-19 frontliners

days in continuance while $28 \%(n=168)$ were performing for more than 7 days in continuation. ( $p$ value $<005)$ (Figure 4).

Area of duty among Covid-19 frontiers Fifty $\%(n=300)$ of the frontiers performed their duty in intensive care units, $22.33 \%(\mathrm{n}=134)$ performed in COVID wards, $10.1 \%(n=61), 9.5 \% n=57$ Sample collection and Triage, while $8 \%(n=48)$ on field duty (Figure 5). 
Behavioral aspect of various section of society towards Covid-19 frontiers

Participants reported that Covid duty Colleagues behavior was very good with a mean score $4.070=4(\mathrm{n} 1=0, \mathrm{n} 2=0$, n3 $=12$ n4= 534 n5=54) (Figure 6).

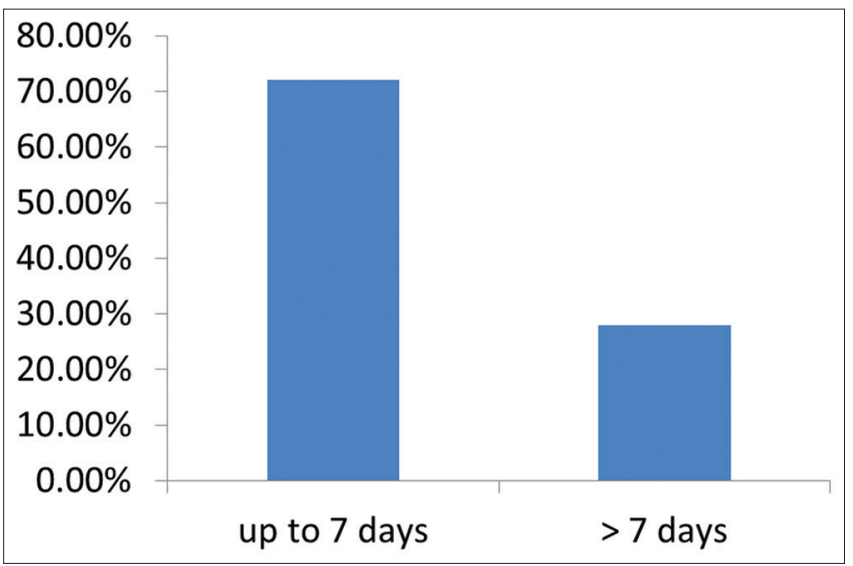

Figure 4: Duration of duty among health care Covid-19 frontiers

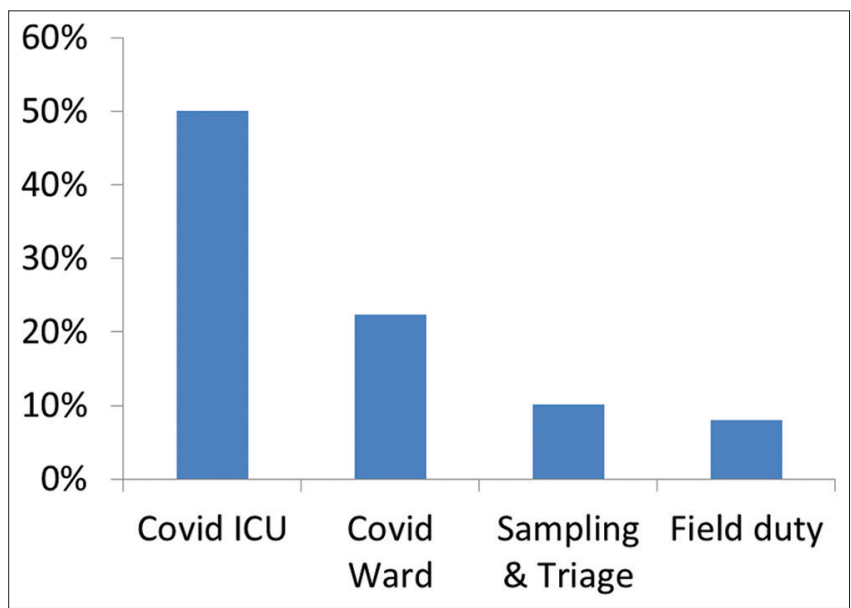

Figure 5: Area of duty among Covid-19 frontiers

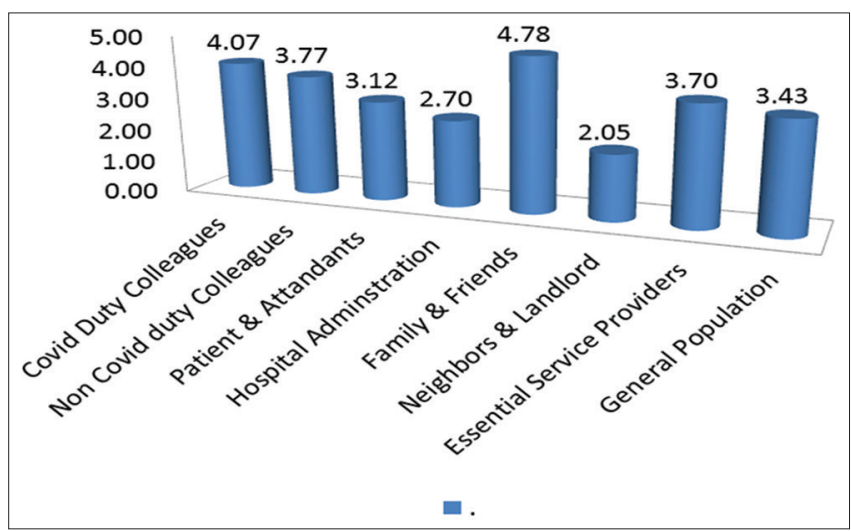

Figure 6: Behavioral aspect of various section of society towards Covid-19 frontiers
Behavior of Non Covid colleagues was very good with a mean score of $3.775=4$ (n1 $=0, \mathrm{n} 2=0, \mathrm{n} 3=256$, $\mathrm{n} 4=223, \mathrm{n} 5=121$ ) (Figure 6).

Behaviors of patients and their attendants was reported as satisfactory with a mean score of $3.12=3(\mathrm{n} 1=5, \mathrm{n} 2=40$, $\mathrm{n} 3=443, \mathrm{n} 4=98, \mathrm{n} 5=14)$ (Figure 6).

Behavior of hospital administrators was reported as satisfactory with a mean score of $2.70=3 \quad$ (n1 $=5$, $\mathrm{n} 2=224, \mathrm{n} 3=324, \mathrm{n} 4=40$ n5=7) (Figure 6).

Behavior of family members was reported as extraordinary with a mean score of $4.775=5 \quad(\mathrm{n} 1=0 \mathrm{n} 2=0 \mathrm{n} 3=5$ $\mathrm{n} 4=125 \mathrm{n} 5=470)$ (Figure 6).

Neighbors and landlord behavior were reported as poor with a mean score of $2.048=2(n 1=182 \mathrm{n} 2=235 \mathrm{n} 3=165$ $\mathrm{n} 4=8 \mathrm{n} 5=10)$ (Figure 6).

Essential service works behavior towards Covid-19 Frontiers was reported as satisfactory with a mean score of $3.70=4(n 1=0 n 2=1 \mathrm{n} 3=287 \mathrm{n} 4=201 \mathrm{n} 5=111)($ Figure 6$)$.

General population behavior towards Covid 19 frontiers was reported as satisfactory with a mean score of $3.43=3(\mathrm{n} 1=0 \mathrm{n} 2=4 \mathrm{n} 3=351 \mathrm{n} 4=223 \mathrm{n} 5=22)$ (Figure 6).

Average mean score was calculated and scored as follow. Decimals were rounded to the nearest whole number (Table 1).

\begin{tabular}{ll} 
Table 1: Behavior response score & \\
\hline 1 & Awful \\
2 & Bad \\
3 & Good/Satisfactory \\
4 & Very Good \\
5 & Extraordinary \\
\hline
\end{tabular}

Health Related Issues faced by health care workers during covid-19 duty

It was observed that among the various health workers, $88.33 \%(n=530)$ of health care worker reported stress during covid-19 duty, $56.16 \%(n=337)$ reported Sleep deprivation and $32.33 \%(n=194)$ reported health related issues (Figure 7).

Opinion of frontline healthcare workers about covid duty

$94.83 \%(n=569)$ were contented for the fraction they contributed during the duties and

$83 \%(\mathrm{n}=498)$ were willing to volunteer for covid-19 duty again (Figure 8). 


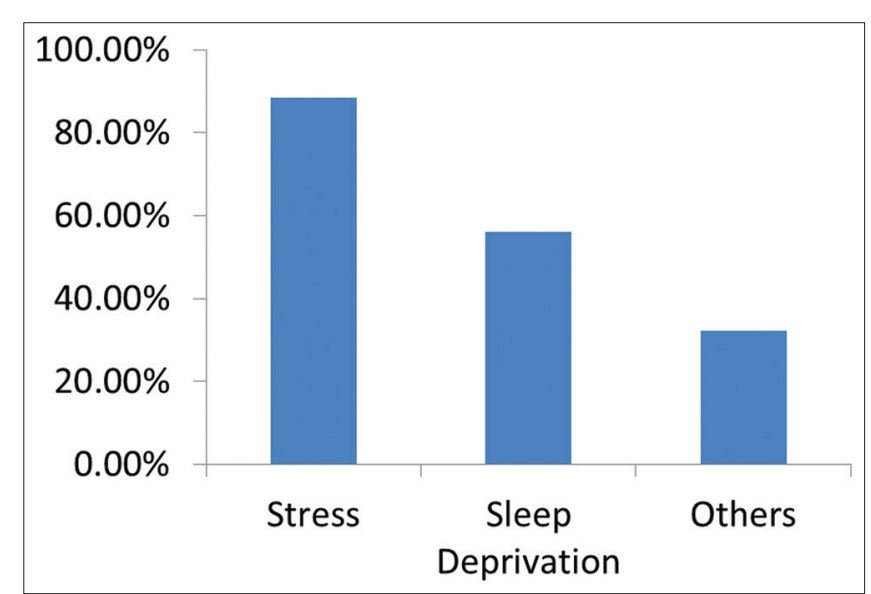

Figure 7: Health related Issues faced by health care workers during covid-19 duty

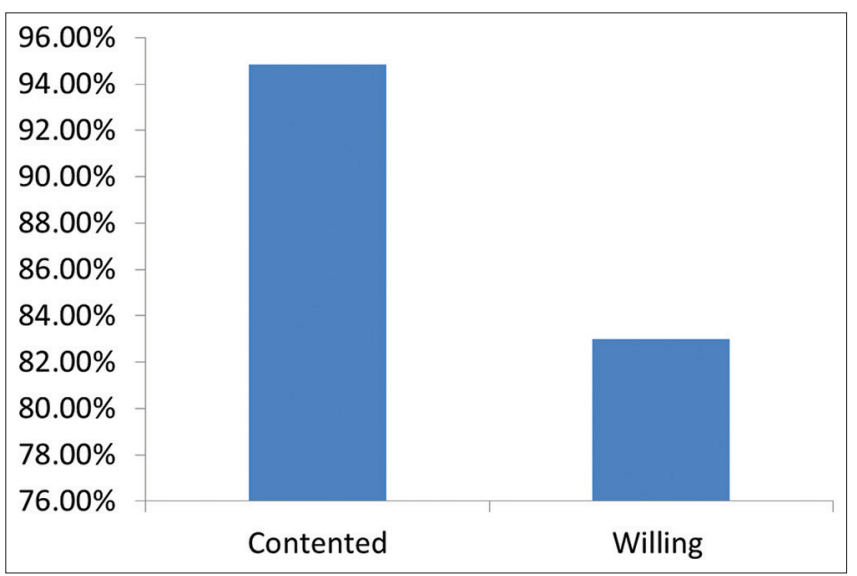

Figure 8: Opinion of frontline healthcare workers about covid duty

\section{DISCUSSION}

In our study we observed that health care workers catering to covid-19 patients services were relatively young and hence beneficial for efficient working of the health care system as reports suggests that case fatality rate of covid-19 is relatively lower among the younger population. ${ }^{8} \mathrm{It}$ was also observed that though most of the participants complained of stress, the duties were kept limited to maximum 7 days in a stretch which helped in decreasing the magnitude of exposure and viral load.

Colleagues supported our participants which lead to friendly work environment and increased work efficiency.

Some reports suggested that Covid patients were usually unhappy with the Covid services provided to them, ${ }^{9,10}$ but our study results contradict their views as patient and their relative behavior was rated satisfactory.

Lockdown period was the period to rejuvenate the health care infrastructure to fight against covid-19 pandemic and hospital administration has played a vital role in providing relevant manpower, equipment, policies and guidelines which has increased health care worker morale. Same is reflected in our study as most of the participants were satisfied with the hospital administration.

In our survey we noted that despite the fact that healthcare workers were fighting against covid-19 and risking themselves and their families but still the neighbors and landlords' behavior was appalling. Several tenant doctors and staff nurses were asked to vacate the premise. ${ }^{11}$ Also few of them were restricted to enter the housing societies while on duty. ${ }^{7}$ This behavioral discrepancy we believe was due to the stigma attached with covid-19 infection. It is a known fact that health care workers are vigilant and aware about the risk involved and so they take all possible mandatory precautions hence we suggest that general population need to be educated and informed more about the disease and awareness campaigns should be initiated to help eliminate the stigma and fear. Government role in this regard is of paramount importance and strict law should be implemented so that health care workers do not face behavioral prejudice.

Friends and family are always supportive and same is reflected in our study. This support extended to our frontline workers not only helped them psychologically but also to keep their morale high which is reflected by their willingness to contribute.

We also observed that while considering health issues majority reported stress and sleep deprivation while some reported other health related issues like fever, myalgia, dehydration etc. These health issues should be addressed with utmost importance and we propose can be solved by considering suggestions of the health workers like setting limitations of duty hours and duty rotation, mandatory quarantine period, improvisation of the work environment along with regular health checkup and psychological counseling and appreciation.

It was overwhelming to see that $94.83 \%$ were contented of their contribution towards fight against Covid 19 and $83 \%$ were ready to volunteer again to perform Covid related duty which reflects their selfless attitude and willingness to serve the society.

\section{CONCLUSION}

Our study concluded that though the overall general population behavior was satisfactory but still behavioral prejudices are existent due to the stigma attached to this pandemic and hence needs to be addressed with great 
concern. We suggest more rigorous public awareness campaigns and mandatory laws to tackle behavior biases. Health related issues should be dealt promptly and psychological counseling should be made mandatory.

\section{ACKNOWLEDGEMENT}

The authors take this opportunity to thank the department of Anaesthesiology and Critical Care for their whole hearted support for this study

\section{REFERENCES}

1. Phelan AL, Katz R and Gostin LO. The Novel Coronavirus Originating in Wuhan, China: Challenges for Global Health Governance. JAMA. 2020;323(8):709=710.

https://doi.org/10.1001/jama.2020.1097

2. Petersen E, Koopmans M, Go U, Hamer DH, Petrosillo N Castelli F, et al. Comparing SARS-CoV-2 with SARS-CoV and influenza pandemics. Lancet Infect Dis. 2020; 20: e238-e244. https://doi.org/10.1016/S1473-3099(20)30484-9

3. WHO Coronavirus Disease (COVID-19) Dashboard. [online] Available at: <https://covid19.who.int> [Accessed 29 August 2020].

4. Alcoba N andAlcoba N. Argentina's Coronavirus Patients, Medical Workers Harassed. [online] Aljazeera.com. Available at: <https:// www.aljazeera.com/indepth/features/argentina-coronaviruspatients-medical-workers-harassed-200428122329108.html> [Accessed 29 August 2020].
5. Japan: Health Care Workers Face Discrimination \& Harassment Over COVID-19. [online] Available at: <https://www.businesshumanrights.org/en/latest-news/japan-health-care-workersface-discrimination-harassment-over-covid-19/> [Accessed 29 August 2020].

6. Russian Federation: Stop Reprisals and Harassment to Frontline Healthcare Workers. [online] Available at: <https://www.amnesty.org/ en/get-involved/take-action/reprisals-and-harassment-of-frontlinehealthcare-workers-must-stop/> [Accessed 29 August 2020].

7. Bose J. DNA India. 2020. Ghaziabad Housing Society Bans Entry of Resident Doctors Out Of COVID-19 Fears; AlIMS RDA Pens Letter to Amit Shah. [online] Available at: <https://www. dnaindia.com/india/report-ghaziabad-housing-society-bansentry-of-resident-doctors-out-of-covid-19-fears-aiims-rda-pensletter-to-amit-shah-2824004> [Accessed 29 August 2020].

8. Li X, Xu S, Yu M, Wang Ke, Tao Y, Zhou Y, et al. Risk factors for severity and mortality in adult COVID-19 inpatients in Wuhan. J Allergy Clin Immunol. 2020;146(1):110-118. https:// doi.org/10.1016/j.jaci.2020.04.006

9. The Indian Express. 2020. Covid-19: Dissatisfied with Hospital, 6 Suspected Patients Return Home in Delhi. [online] Available at: $<$ https://indianexpress.com/article/cities/delhi/dissatisfied-withhospital-6-suspected-patients-return-home-in-delhi-6322814/> [Accessed 29 August 2020]

10. Yasmeen A. Coronavirus: Patients Upset with Lack of Personal Hygiene in Isolation Ward. [online] The Hindu. Available at: $<$ https://www.thehindu.com/news/national/karnataka/coronavirus - patients-upset-with-lack-of-personal-hygiene-in-isolatio n-ward/ article30686053.ece> [Accessed 29 August 2020].

11. Joy S. Amidst COVID-19 Outbreak, Landlords Ask Doctors, Nurses to Vacate Houses; Govt Warns Owners. [online] Deccan Herald. Available at: <https://www.deccanherald.com/national/amidst-covid19-outbreak-landlords-ask-doctors-nurses-to-vacate-houses-govtwarns-owners-817435.html> [Accessed 29 August 2020].

\footnotetext{
Author's Contribution:

MG and TY-Concept and design of the study, Manuscript preparation, Data analysis and Interpretation of results, reviewed the literature and manuscript preparation; HSW- Interpreted the results; reviewed the literature and manuscript preparation; SJ-Statistical analysis and Interpretation, preparation of manuscript and revision of the manuscript.

Work Attributed to:

Pt BD Sharma PGIMS Rohtak, Haryana, India.

Orcid ID:

Dr Mayuri Golhar- (1) https://orcid.org/0000-0002-1653-3261

Dr Tarun Yadav- (i) https://orcid.org/0000-0003-4943-1031

Dr Harsimran Singh Walia- (D) https://orcid.org/0000-0002-5058-5137

Dr Sanjay Johar- (i) https://orcid.org/0000-0002-1039-1469

Source of funding: None, Conflict of Interest: None
} 